\title{
A STUDY OF PRIMARY NUTRIENT FORAMINA IN FEMUR
}

\author{
Aswathy Maria Oommen', Latha Sreedhar Lekshmy Sreedhar², Suja Robert Joseph Sarasammal', Sheena Kalyani Sukumaran ${ }^{4}$
}

${ }^{1}$ Assistant Professor, Department of Anatomy, Government Medical College, Thiruvananthapuram, Kerala, India. ${ }^{2}$ Associate Professor, Department of Anatomy, Government Medical College, Thiruvananthapuram, Kerala, India. ${ }_{3}^{3}$ Assistant Professor, Department of Anatomy, Government Medical College, Thiruvananthapuram, Kerala, India. ${ }^{4}$ Assistant Professor, Department of Anatomy, Government Medical College, Thiruvananthapuram, Kerala, India. ABSTRACT

\section{BACKGROUND}

Nutrient foramina are seen in all long bones. They vary in number, size and their position on the surface of the bones. These foramina are significant, as nutrient arteries which are the main source of blood supply to long bones, pass through them to vascularise the bones. Of the primary and secondary nutrient foramina that are seen in bones, the main nutrient artery enters through the primary foramen. Data obtained from the study of parameters like number, site of entry, direction of nutrient foramina will be of immense value to surgeons, orthopaedicians and radiologists while performing various procedures.

The aim of this study was to identify the number, type, location and direction of foramina and calculate the foraminal index.

\section{MATERIALS AND METHODS}

The descriptive study was done using 121 femora. The length of each bone and distance of the primary nutrient foramen from the upper end of the bone was measured using an osteometric board. The location of the foramina on the surface of the bone, direction of the nutrient canal and presence of secondary foramina were noted. The bones of the right and left sides were compared.

\section{RESULTS}

In most of the femora, there was a single primary nutrient foramen located on the posterior surface in the middle segment and directed proximally, whereas a few of the bones had no primary nutrient foramina and a few had two.

\section{CONCLUSION}

To facilitate a better outcome for all radiological and surgical procedures, clinicians must be aware of variations from the normal anatomy. The findings from this study will definitely aid them in this aspect. Stature of an individual can be measured from the position of primary nutrient foramen in forensic investigations.

\section{KEY WORDS}

Femur, Nutrient foramen, Osteometric Board, Foraminal Index.

HOW TO CITE THIS ARTICLE: Oommen AM, Sreedhar LSL, Sarasammal SRJ, et al. A study of primary nutrient foramina in femur. J. Evolution Med. Dent. Sci. 2018;7(36):4032-4034, DOI: 10.14260/jemds/2018/900

\section{BACKGROUND}

The long bones of the human body are supplied by diaphyseal, epiphyseal, metaphyseal and periosteal arteries through several points of inflow. ${ }^{1}$ One or two nutrient (Diaphyseal) arteries supply the diaphysis of the shaft through the nutrient foramina, which lead into nutrient canals. ${ }^{1}$ The nutrient arteries are the main source of supply to the bone and play an important role in bone vascularisation and growth. ${ }^{2}$

Nutrient foramina are positioned on the flexor aspect of the long bones.2,3 They are directed away from the growing end of the bone. Their direction is indicated by the phrase "to the elbow I go; from the knee I flee." 4 A distinct groove leads to the primary nutrient foramen and the edges of the foramen are slightly raised. ${ }^{5}$ In femur they are directed proximally, are located on the linea aspera and vary in number and site. ${ }^{1}$

'Financial or Other Competing Interest': None.

Submission 11-07-2018, Peer Review 19-08-2018,

Acceptance 25-08-2018, Published 03-09-2018.

Corresponding Author:

Dr. Aswathy Maria Oommen,

Ivelil, Kamal Nagar, Nalanchira P. O.,

Thiruvananthapuram-695015,

Kerala, India.

E-mail: aswathyivelil@yahoo.co.in

DOI: $10.14260 /$ jemds $/ 2018 / 900$
The number, site of entry and direction of nutrient foramina are almost constant. ${ }^{1}$ There are many studies describing variations of these parameters. $4,6,7,8,9$ The surgeons must be aware of such variations while conducting fracture fixation, bone grafting, tumour resection etc. to ensure a successful procedure and a better prognosis. ${ }^{4}$ Data obtained from a study of these parameters will be of paramount importance to surgeons, orthopaedicians and radiologists alike.

The study parameters will also be useful in anthropological and medico-legal studies, as the length of a bone can be calculated from the distance of the nutrient foramen from either end of the bone. This value can then be used to reconstruct the height of an individual. ${ }^{10}$

\section{MATERIALS AND METHODS}

The descriptive study sample consisted of 121 fully ossified intact adult femora obtained from the Department of Anatomy, Government Medical College, Thiruvananthapuram. The bones were unpaired and of unknown sex. Bones that were damaged or deformed were not taken for the study. Of the 121 femora, 54 belonged to the right and 67 to the left side.

The right and left limb bones were measured. The total length of each femur from the uppermost point on the head of femur to the lower end was measured using an osteometric board. The total length was divided into three segments- 
upper, middle and lower by marking a distance of 10, 20 and $30 \mathrm{~cm}$ from the upper end of the bone. Primary Nutrient Foramina (PNF) were identified by the presence of a welldefined groove leading to it. Foramina that allowed the passage of a 24-gauge needle were considered as primary and those with a lesser diameter as secondary nutrient foramina (Fig. 1). The number, direction and position on the surface of bone of the PNF were noted. The distance of the primary foramen from the upper end of the femur was also measured using the osteometric board.

The following Study Parameters were Measured/ Observed

1. Total length of femur (L).

2. Number of Primary Nutrient Foramina (PNF).

3. Distance of the PNF from the upper end of femur (D) and the segment in which it is present was noted.

4. Foraminal Index (FI) calculated using Hughes formula ${ }^{10}$ : $\mathrm{FI}=[\mathrm{D} / \mathrm{L}] \times 100$.

5. Location of the PNF on the surface of femur and direction.

6. The parameters of the right and left sides were compared.

7. Number of secondary nutrient foramina.

Data was analysed using trial version of SPSS ver. 22. The results were compared with the observations of other studies. Linear regression analysis was done to establish the relationship between $\mathrm{L}$ and $\mathrm{D}$.

\section{RESULTS}

The mean total length of femur of the right side was $41.97 \pm$ $3.14 \mathrm{~cm}$ and on the left side was $41.86 \pm 3.64 \mathrm{~cm}$. The mean distance of the nutrient foramen from the upper end of femur on the right was $18.49 \pm 4.61 \mathrm{~cm}$ and on the left side $17.22 \pm$ $4.03 \mathrm{~cm}$. The foraminal index was calculated for each bone and the mean value was noted to be $44.17 \pm 10.26$ and 41.28 \pm 10.12 on the right and left sides respectively, (Table 1).

of the 54 right femora 45 had only a single primary nutrient foramen, 4 had two, whereas 5 had none. Of these 5 one had no primary or secondary foramina, whereas the other four had secondary foramina. Of the 67 left femora 59 had only a single primary nutrient foramen, 5 had two, whereas 3 had none. One of these 3 had no nutrient foramen, neither primary nor secondary. The other two had secondary nutrient foramina (Table 2).

$62.26 \%$ of the PNF on the right bones and $71.01 \%$ of PNF on the left were located in the middle segment. Most of the secondary foramina were also located in the middle segment of femur (Table 3).

The PNF were mostly located on the posterior surface of femur between the lips of the linea aspera. $45.28 \%$ of PNF of the right and $71.01 \%$ of the left were located on the linea aspera between the lips. The next common location was on the medial lip of the linea aspera with $30.19 \%$ of PNF of the right and $13.04 \%$ of the left (Table 4 ).

Pearson correlation showed a positive correlation between total length of femur ( $\mathrm{L}$ ) and distance of the PNF from the upper end of femur (D) with $r=0.260$ and $p=0.004$. Linear regression analysis was done to establish the relationship between $\mathrm{L}$ and $\mathrm{D}$ and an equation was derived for estimation of L using D:- $L=38.406+0.194 \times$ D
This equation can be used to calculate the total length of femur and thereby the stature of the individual, if the distance of the PNF from the upper end of femur is obtained. Vice-versa, if $L$ is known, the position of the PNF from the upper end of femur can also be calculated.

\begin{tabular}{|c|c|c|c|}
\hline & $\begin{array}{c}\text { Total Length } \\
\text { of Bone }\end{array}$ & $\begin{array}{c}\text { Distance of PNF } \\
\text { from Upper End of } \\
\text { Bone }\end{array}$ & $\begin{array}{c}\text { Foraminal } \\
\text { Index }\end{array}$ \\
\cline { 2 - 4 } & Mean with SD & Mean with SD & Mean with SD \\
\hline $\begin{array}{c}\text { Right } \\
\text { N=54 }\end{array}$ & $41.97 \pm 3.14$ & $18.49 \pm 4.61$ & $44.17 \pm 10.26$ \\
\hline $\begin{array}{c}\text { Left } \\
\text { N=67 }\end{array}$ & $41.86 \pm 3.64$ & $17.22 \pm 4.03$ & $41.28 \pm 10.12$ \\
\hline P & 0.926 & 0.161 & 0.165 \\
\hline
\end{tabular}

Table 1. Measurements of Total Length of Femur, Primary Nutrient Foramina and Foraminal Index

PNF- Primary Nutrient Foramina.

\begin{tabular}{|c|c|c|c|c|c|c|}
\hline & \multicolumn{3}{|c|}{ Right N= 54 } & \multicolumn{3}{c|}{ Left N= 67 } \\
\hline No. of foramina & 0 & 1 & 2 & 0 & 1 & 2 \\
\hline No. of bones & 5 & 45 & 4 & 3 & 59 & 5 \\
\hline Percentage & 9.26 & 83.33 & 7.41 & 4.48 & 88.06 & 7.46 \\
\hline
\end{tabular}

Table 2. Incidence of Primary Nutrient Foramina

\begin{tabular}{|c|c|c|c|c|c|}
\hline \multirow[b]{2}{*}{ Right $N=54$} & \multicolumn{2}{|c|}{ Total No. of PNF } & \multirow[b]{2}{*}{$\begin{array}{l}\text { Left } \\
N=67\end{array}$} & \multicolumn{2}{|c|}{ Total No. of PNF } \\
\hline & $\begin{array}{l}\text { NF } \\
(53)\end{array}$ & Percentage & & $\begin{array}{c}\text { NF } \\
(69)\end{array}$ & Percentage \\
\hline $\begin{array}{c}\text { Upper } 1 / 3 \mathrm{rd} \\
10 \mathrm{~cm}\end{array}$ & 0 & 0 & & 0 & 0 \\
\hline $\begin{array}{c}\text { Middle } 1 / 3 \mathrm{rd} \\
20 \mathrm{~cm}\end{array}$ & 33 & 62.26 & & 49 & 71.01 \\
\hline $\begin{array}{c}\text { Lower } 1 / 3 \mathrm{rd} \\
30 \mathrm{~cm}\end{array}$ & 20 & 37.74 & & 20 & 28.99 \\
\hline
\end{tabular}

Table 3. Segmental Position of Primary Nutrient Foramina

\begin{tabular}{|c|c|c|c|c|}
\hline \multirow{2}{*}{$\begin{array}{c}\text { Location } \\
\text { (in Relation to Linea } \\
\text { Aspera) }\end{array}$} & \multicolumn{4}{|c|}{ No. of Primary Nutrient Foramina } \\
\hline & $\begin{array}{l}\text { Right } \\
\text { (53) }\end{array}$ & $\%$ & $\begin{array}{l}\text { Left } \\
(69)\end{array}$ & $\%$ \\
\hline Between the two lips & 24 & 45.28 & 49 & 71.01 \\
\hline On medial lip & 16 & 30.19 & 9 & 13.04 \\
\hline On lateral lip & 8 & 15.10 & 6 & 8.70 \\
\hline Postero-medial surface & 3 & 5.66 & 2 & 2.90 \\
\hline Postero-lateral surface & 2 & 3.77 & 3 & 4.35 \\
\hline \multicolumn{5}{|c|}{$\begin{array}{l}\text { Table 4. Location of Primary Nutrient } \\
\text { Foramina on Surface of Femur }\end{array}$} \\
\hline
\end{tabular}

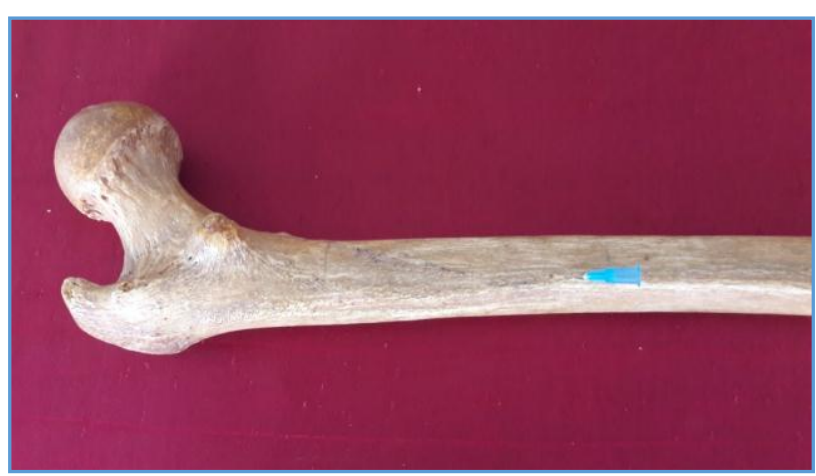

Figure 1. Primary Nutrient Foramen

The needle is inserted into the primary nutrient foramen. The foramen is located between the lips of the linea aspera and is directed towards the upper end of femur. 


\section{DISCUSSION}

Krishna SM et al in their study on primary nutrient foramina of femur observed that all the nutrient foramina were directed towards the upper end of the bone. They identified 2, 3 and 4 foramina in different bones. ${ }^{2}$ The PNF identified in all the 121 femora in the present study were also directed towards the upper end of the bones. A single diaphyseal nutrient foramen, which was directed away from the growing ends (upper ends) was noted by Kamath $\mathrm{V}$ et al in their study on tibia and fibula. ${ }^{5}$

Kamath $\mathrm{V}$ et al also calculated the foraminal index of these bones and found their findings similar to other previous studies. ${ }^{5}$ Hughes formula for Foraminal Index (FI) was used: FI= PF/TL $x 100$, where PF is the distance of the foramen from the proximal end of the bone and TL is the total length of the bone. In tibia most of the foramina were in the upper third and in fibula the middle third. According to Krishna SM et al, the foramina were located mostly in the middle third of the shaft of femur. ${ }^{2}$ This is similar to the present study.

Kamath $\mathrm{V}$ et al and Verma $\mathrm{P}$ et al in their study concluded that the nutrient foramina of femur, tibia and fibula were located on the posterior surface (i.e. the flexor aspect) of the bones mainly.5,7 Similar studies have been conducted on different bones and variations in the number and position of nutrient foramina have been noted. $4,8,9$ In this study too variations in the number of PNF were observed and they were all located on the posterior surface of femur. We agree as quoted in the study by Muralimanju BV et $\mathrm{al}^{6}$ that the length of femur cannot be calculated from the number of PNF.

In this study, we found a positive correlation between the length of femur and the position of the PNF and have derived an equation to calculate the total length of femur from the distance of the PNF from the upper end of femur. This will definitely be valuable for the forensic science experts to calculate the stature of an individual. The surgeons on the other hand will find it useful to calculate the position of the PNF from the total length of femur.

\section{CONCLUSION}

The nutrient artery enters a bone through its primary diaphyseal nutrient foramen usually and is the major source of vascularisation to the bone. It is absolutely essential for the surgeon to have a sound knowledge of the location and number of these foramina, so as to prevent any inadvertent injuries during surgery. The present study of these parameters will provide useful data and aid those undertaking surgical interventions of femur.

This study is also useful for forensic experts for the calculation of the total length of femur from the distance of the primary nutrient foramen from its upper end. This measurement can aid in the estimation of the stature of an individual.

\section{ACKNOWLEDGEMENTS}

The authors gratefully acknowledge the help and support given by Dr. K Renuka, Professor and Head of the Department of Anatomy, Government Medical College, Thiruvananthapuram and Dr. Sasikala K, Professor and Head of the Department of Forensic Medicine, Government Medical College, Thiruvananthapuram and Mr. Jayakumar P for his valuable advice in the statistical analysis of this work.

\section{REFERENCES}

[1] Standring S. Gray's anatomy: the anatomical basis of clinical practice. $41^{\text {st }}$ edn. Elsevier Health Sciences 2015.

[2] Krishna MS, Kumar UP, Sirisha V, et al. Morphologic and morphometric study of the nutrient foramina in dry human femur bones of telangana region. International Journal of Anatomy and Research 2016;4(2):2464-8.

[3] Longia GS, Ajmani ML, Saxena SK, et al. Study of diaphyseal nutrient foramina in human long bones. Acta Anat (Basel) 1980;107(4):399-406.

[4] Rao VS, Kothapalli J. The diaphyseal nutrient foramina architecture - a study on the human upper and lower limb long bones. IOSR J Pharm Biol Sci 2014;9:36-41.

[5] Kamath V, Asif M, Bhat S, et al. Primary nutrient foramina of tibia and fibula and their surgical implications. Indian Journal of Clinical Anatomy and Physiology 2016;3(1):41-4.

[6] Muralimanju BV, Prashanth KU, Prabhu LV, et al. Morphological and topographical anatomy of nutrient foramina in human upper limb long bones and their surgical importance. Rom J Morphol Embryol 2011;52(3):859-62.

[7] Seema, Verma P, Mahajan A, et al. Variation in the number and position of nutrient foramina of long bones of lower limb in north Indians. Int J Anat Res 2015;3(4):1505-09.

[8] Kizilkanat E, Boyan N, Ozsahin ET, et al. Location, number and clinical significance of nutrient foramina in human long bones. Annals of AnatomyAnatomischer Anzeiger 2007;189(1):87-95.

[9] Malukar 0, Joshi H. Diaphysial nutrient foramina in long bones and miniature long bones. NJIRM 2011;2(2):23-6.

[10] Hughes $\mathrm{H}$. The factors determining the direction of the canal for the nutrient artery in the long bones of mammals and birds. Acta Anat (Basel) 1952;15(3):261-80. 